\title{
A non-instantaneous inventory model having different deterioration rates with stock and price dependent demand under partially backlogged shortages
}

\author{
Abu Hashan Md Mashud ${ }^{a^{*}}$, Md. Al-Amin Khan ${ }^{\mathrm{b}}$, M. Sharif Uddin ${ }^{\mathrm{b}}$ and M. Nazrul Islam ${ }^{\mathrm{b}}$
}

${ }^{a}$ Department of Mathematics, Hajee Mohammad Danesh Science and Technology University, Dinajpur-5200, Bangladesh ${ }^{b}$ Department of Mathematics, Jahangirnagar University, Savar, Dhaka-1342, Bangladesh

\begin{tabular}{l}
\hline C H R O N I C L E \\
\hline Article history: \\
Received December 2, 2016 \\
Received in revised format \\
December 10, 2016 \\
Accepted June 12017 \\
Available online \\
June 12017 \\
\hline Keywords: \\
Inventory \\
Constant deterioration \\
Partially backlogged \\
shortages \\
Price dependent demand \\
Stock dependent demand \\
Non-instantaneous
\end{tabular}

\section{Introduction}

Traditionally, deterioration of any good can be defined as decay, change, damage, spoilage or obsolescence, which results in decreasing usefulness from its original purpose. There are various kinds of products such as vegetables, fruit, etc. subject to deterioration in inventory. Recently, according to the existing literature, many researchers/scientists have investigated different types of inventory models by considering the product as a deteriorating item. The deterioration is one of the essential aspects in inventory analysis. However, the deteriorating products are not useable. So we cannot ignore this fact and its consequence to inventory analysis. Ghare and Schrader (1963) first established an economic order quantity model over a finite planning horizon having a constant rate of demand and a constant rate of deterioration. Covert and Philip (1973) converted Ghare and Schrader's model of constant deterioration rate to a model having two parameter Weibull distribution. 
In real world, not all kinds of inventory items do they deteriorate as soon as they are received by the retailer. The product has no deterioration and keeps its original quality in the fresh product time. Ouyang et al. (2006) called this phenomenon as "non-instantaneous deterioration", and based on this they established an inventory model for non-instantaneous deteriorating items with consideration of permissible delay in payments.

Since Harris (1913) presented an economic quantity (EOQ) model and many researchers have used it to adjust their assumptions to realistic situations in inventory management. For instance, it is usually observed that a large scale of products displayed in the super market attracts more customers and generates a higher demand (Levin et al., 1972). The inventory problem has become an important issue that received considerable attention in inventory models with stock-dependent demand rates. Gupta and Vrat (1986) first developed an inventory model for stock-dependent consumption rates.

Baker and Urban (1988) developed an EOQ model by considering stock-dependent demand pattern in power form. Mandal and Phaujdar (1989) proposed an EPQ model based on a constant production rate and linearly stock-dependent demand for deteriorating items. Datta and Pal (1990) proposed an inventory model where the demand rate is a piecewise function of the inventory level. Pal et al. (1993) extended Baker and Urbans (1988) model for deteriorating items. Vrat and Padmanabhan (1995) developed an inventory model by considering stock-dependent selling rate and shortage for deteriorating items. Sarker et al. (1997) developed a model for order level lot size with consideration of inventory level dependent demand and deterioration. Ray and Chaudhuri (1997) developed an EOQ model with stock-dependent demand, shortage, inflation and time discounting. Ray et al. (1998) modified this model by considering two levels of storage and stock-dependent demand rate. Wu et al. (2006) developed a replenishment model for non-instantaneous deteriorating items with stock dependent demand and partial backlogging. Lee and Dye (2012) worked on an inventory model considering stock dependent demand and controllable deterioration rate for deteriorating items. Min et al. (2012) also developed an EPQ model for deteriorating items with inventory-level-dependent demand and permissible delay in payments. Avinadav et al. (2013) made an optimal inventory policy for a perishable item with demand function sensitive to price and time. Taleizadeh et al. (2013) developed an economic order quantity model with a known price increase and partial back ordering. In the present era of competitive market, the effect of price variations and the advertisement of an item change its demand pattern amongst the public. To promote the business the propaganda and canvassing of an item by advertisement in the well-known media such as T.V, Newspaper, Radio, Online Advertisement, Magazine, Cinema, etc. and lastly also through the sales representatives have a motivational effect on people. Also, the product pricing of an item is one of the decisive factors in selecting an item for use. In recent days the common observation on market shows that higher selling price decreases demand whereas lower selling price has the reverse effect. The demand of an item is a function of displayed inventory in a show-room, selling price of that inventory and the advertisement expenditures frequency of advertisement. It is rarely studied the effects of price variations and advertisement on the demand rate of the items by OR researchers and practitioners. Kotler (1971) established marketing policies into inventory decisions and discussed the relationship between pricing decision and economic order quantity. Ladany and Sternleib (1974) studied the effect of price variation on EOQ as well as on selling. However, they did not consider the effect of advertisement. Subramanyam and Kumaraswamy (1981) considered an EOQ formula under varying marketing policies and conditions. Then, Urban (1992) extended it for a model of deterministic inventories by incorporating marketing decisions. Goyal and Gunasekaran (1995) considering marketing policies developed a production marketing model for deteriorating items. Abad (1996) considered optimal pricing and lot sizing under conditions of perishability and partial backordering. Pal et al. (2007) then extended this by considering partially integrated production and marketing policy with variable demand under flexibility and reliability via Genetic algorithm. Bhunia and Shaikh (2011) developed an inventory model incorporating the effects of price variations and advertisement on the demand rate of an item. 
The authors mentioned above have considered different deterioration and different types of demand. The items may become damaged due to the expiration date of the life time of products. Deterioration rate of the items is directly proportional to the maximum life time, which may be controlled the maximum life time of the produced items. An inventory model with shortage, ramp-type demand rate and time dependent deterioration rate was discussed by Giri et al. (2003). Manna and Chaudhuri (2006) introduced an EOQ model for items with deterioration and time-dependent demand. An inventory model with Weibull deterioration rate, general ramp type demand rate and partial backlogging, was considered by Skouri et al. (2009). Sana (2010b) developed an EOQ model with partial backlogging rate and time varying deterioration. Sarkar (2012a) introduced an EOQ model for finite replenishment rate considered the demand and deterioration rate were both dependent on time. Sett et al. (2012) developed two warehouse inventory models with time dependent deterioration and quadratic demand. Sarkar (2012b) discussed a production-inventory model with three different types of continuously distributed deterioration functions.

In this paper an inventory model is described according to - price, stock dependent demand, two different constant deteriorations and partially backlogged shortages. In this model it is assumed the demand function is dependent on price during the interval $\left[0, t_{1}\right]$ and dependent on price and stock in the interval $\left[t_{1}, t_{d}\right]$ and in shortage time $\left[t_{d}, T\right]$. The deterioration is considered as non-instantaneous, which means that when the item in retailer's house after any time deterioration is likely to begin with a constant rate for certain period, then due to the effect of time and different parameters the deterioration will increase. Then after shortages appear and it is partially backlogged. The corresponding inventory problem constitutes a constraint optimization problem. Here this problem is solved by using Matlab software. And to show the convexity of the cost function, a graph is given in (Figure 2) with the help of this software. Finally, to illustrate and validate the inventory model, we have used a numerical example when the fixed price is used. A sensitivity analysis has been carried out to study the effect of changes of different inventory parameters changing one parameter at a time holding other parameter remained unchanged. .

\section{Assumptions and Notations}

The proposed mathematical model presented in this paper is based on the following assumptions.

1. Replenishment rate is infinite and lead-time is negligible.

2. Demand rate $D(p)= \begin{cases}a-b p & \text { when } I(t) \in\left[0, t_{1}\right] \\ a-b p+c I(t) & \text { when } I(t) \in\left[t_{1}, t_{d}\right] \text { i.e., when } I(t) \geq 0 \text { demand is dependent on price } \\ \delta(a-b p) & \text { when } I(t) \in\left[t_{d}, T\right]\end{cases}$ in the interval $\left[0, t_{1}\right]$ and on selling price as well as stock in the interval $\left[t_{1}, t_{d}\right]$ and when $I(t)<0$ demand is dependent only on price.

3. The planning horizon of the inventory system is infinite.

4. Within the time interval $\left[0, t_{1}\right]$, the product has no deterioration. Deterioration occurs in the time interval $\left[\mathrm{t}_{1}, \mathrm{td}\right]$ at two different constant rates $\alpha$ and $\beta$.

5. $\mathrm{I}_{1}(\mathrm{t})$ denotes the inventory level at any time $t \in\left[0, \mathrm{t}_{1}\right]$, without the deterioration of product. $\mathrm{I}_{2}(\mathrm{t})$ stands for the inventory level at any time $t \in\left[\mathrm{t}_{1}, \mathrm{t}_{2}\right]$, with the deterioration of product.

$\mathrm{I}_{3}(\mathrm{t})$ stands for the inventory level at any time $t \in\left[\mathrm{t}_{2}, \mathrm{t}_{\mathrm{d}}\right]$, with the deterioration of product.

$\mathrm{I}_{4}(\mathrm{t})$ stands for the inventory level at any time $t \in\left[\mathrm{t}_{d}, \mathrm{~T}\right]$, with the shortage of product.

6. Shortages are allowed and during the stock out period, a fraction $\delta$ of the demand will be backorder, and the remaining fraction $(1-\delta)$ will be lost.

\section{Notations}

In addition, the following nomenclatures are used in the paper development. 


\begin{tabular}{|c|c|c|}
\hline Notations & Units & Description \\
\hline$c_{o}$ & \$/unit & replenishment cost per order \\
\hline$c_{p}$ & \$/unit & purchasing cost per unit \\
\hline$c h$ & \$/unit & holding cost per unit for per unit of time \\
\hline$c b$ & \$/unit & shortage cost per unit for per unit of time \\
\hline$\alpha, \beta$ & constant & Deterioration rates. \\
\hline$S$ & units & maximum number of units in stock per cycle \\
\hline$p$ & \$/unit & selling price \\
\hline$R$ & unit & maximum units in shortage level \\
\hline$I(t)$ & units & inventory level at any time $t$ where $0 \leq t \leq T$ \\
\hline$T C\left(\mathrm{t}_{1}, \mathrm{~T}\right)$ & \$/year & the total cost per unit time \\
\hline
\end{tabular}

Decision variables

$\begin{array}{lll}t_{1} & \text { year } & \begin{array}{l}\text { time at which the inventory level reaches to w where } 0<\mathrm{w}<\mathrm{S} \text { and } \\ \text { deterioration start with constant rate } \alpha\end{array} \\ t_{2} & \text { year } & \text { Time at which the inventory level decreases due to deterioration rate } \beta . \\ t_{d} & \text { Year } & \text { Time at which the inventory level reaches to zero. } \\ T & \text { Year } & \text { The length of the replenishment cycle. }\end{array}$

\section{Mathematical Model Formulation for inventory model.}

An inventory model based on the above mentioned assumptions and notations has been developed in this paper. Using above assumptions, the inventory level follows the pattern depicted in Fig. 1.

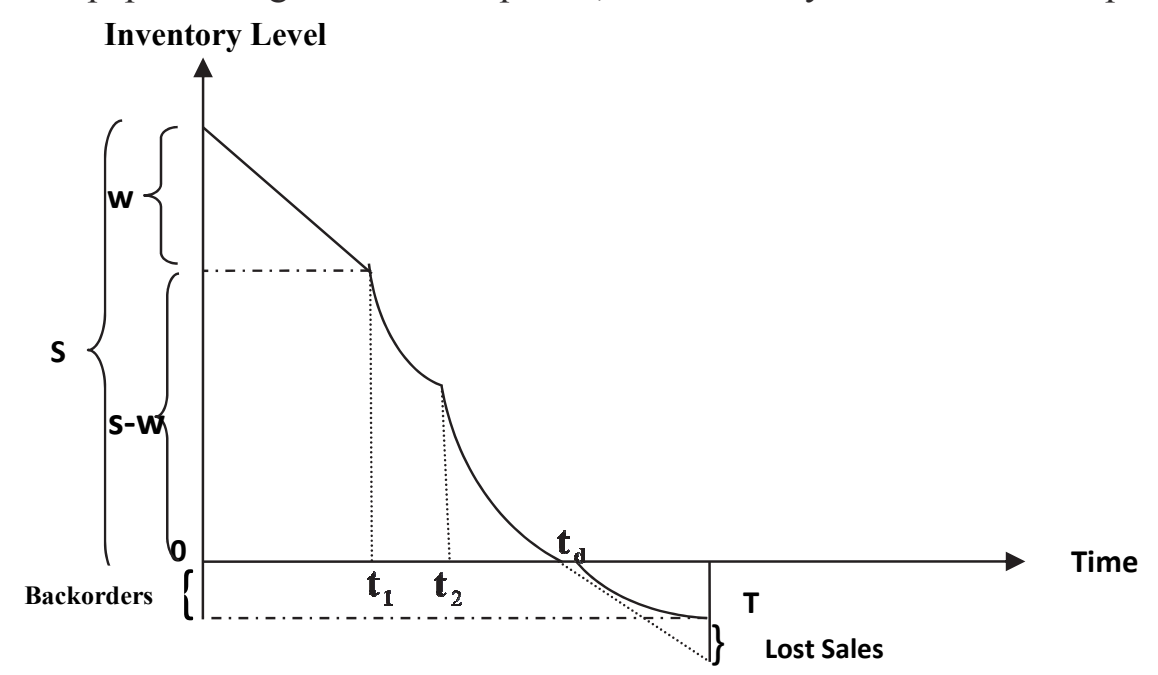

Fig. 1. Graphical presentation of the inventory system: inventory versus time.

Initially an enterprise purchased $(S+R)$ units of goods. This stock depletes to meet up the customer demands and deterioration. After time $t_{l}$ the deterioration will start with a rate $\alpha$, but due to time effect this deterioration will increase to rate $\beta$ after time $t_{2}$. At time $t=t_{d}$ stock level is zero. As shortage appears, shortages are to be partially backlogged with a rate $\delta$. Therefore, the inventory system can be described by the following differential equation considering $D=a-b p$ :

$\frac{d I_{1}(t)}{d t}=-D, 0 \leq t \leq t_{1}$

with the condition $I_{1}(t)=$ Wat $t=0, I_{1}(t)=0$ at $t=t_{1}$

$$
\frac{d I_{2}(t)}{d t}+\alpha I_{2}(t)=-\left[D+c I_{2}(t)\right], t_{1}<t \leq t_{2}
$$


with $I_{2}\left(t_{1}\right)=S-W, I_{2}\left(t_{2}\right)$ is continuous.

$$
\frac{d I_{3}(t)}{d t}+\beta I_{3}(t)=-\left[D+c I_{3}(t)\right], t_{2}<t \leq t_{d}
$$

with $I_{3}\left(t_{d}\right)=0$

$$
\frac{d I_{4}(t)}{d t}=-\delta D, t_{d}<t \leq T
$$

with $I_{4}\left(t_{d}\right)=0, I_{4}(T)=-R$

\section{Solution of differential equations from 1-4:}

From Eq. (1) we have

$$
I_{1}(t)=-D t+k \quad 0 \leq t \leq t_{1}
$$

Using the condition $I_{1}(t)=W$ at $t=0$, it is found that

$$
I_{1}(t)=W-D t
$$

Also $I_{1}(t)=0$ at $t=t_{1}$ we have

$$
t_{1}=\frac{W}{D}
$$

From Eq. (2) we have

$$
I_{2}(t)=\frac{-D}{(\alpha+c)}+k e^{-(\alpha+c) t} \quad t_{1}<t \leq t_{2}
$$

Using the condition $I_{2}(t)=S-W$ at $t=t_{1}$ and $I_{2}\left(t_{2}\right)$ is continuous, it is obtained that

$$
I_{2}(t)=\frac{-D}{(\alpha+c)}+\left\{S-W+\frac{D}{(\alpha+c)}\right\} e^{(\alpha+c)\left(t_{1}-t\right)}
$$

From Eq. (3) we have

$$
I_{3}(t)=\frac{-D}{(\beta+c)}+k e^{-(\beta+c) t} \quad t_{2}<t \leq t_{d}
$$

Using the condition $I_{3}(t)=0$ at $t=t_{d}$, it comes to

$$
I_{3}(t)=\frac{D}{(\beta+c)}\left\{e^{(\beta+c)\left(t_{d}-t\right)}-1\right\}
$$

Using continuity at the point $t=t_{2}$, it gives $I_{2}\left(t_{2}\right)=I_{3}\left(t_{2}\right)$ i.e.

$$
\frac{-D}{(\alpha+c)}+\left\{S-W+\frac{D}{(\alpha+c)}\right\} e^{(\alpha+c)\left(t_{1}-t_{2}\right)}=\frac{D}{(\beta+c)}\left\{e^{(\beta+c)\left(t_{d}-t_{2}\right)}-1\right\}
$$

This implies that, $S=W-\frac{D}{\alpha+c}+\frac{D}{\alpha+c} e^{-(\alpha+c)\left(t_{1}-t_{2}\right)}+\frac{D}{\beta+c}\left\{e^{(\beta+c)\left(t_{d}-t_{2}\right)}-1\right\} e^{-(\alpha+c)\left(t_{1}-t_{2}\right)}$

From Eq. (4),

$$
I_{4}(t)=-\delta D t+k
$$

Using the condition $I_{4}(t)=0$ at $t=t_{d}$, it is obtained

$$
I_{4}(t)=\delta D\left(t_{d}-t\right)
$$

Again using the condition $I_{4}(T)=-R$

It is $R=\delta D\left(T-t_{d}\right)$

The total cost per unit time for the inventory system consists of the following components.

\section{The total cost per unit time}


a) Ordering cost per cycle $=\mathrm{C}$

b) The inventory holding cost per cycle $(\mathrm{HC})=c_{h}\left[\int_{0}^{t_{1}}\left[I_{1}(t) d t+\int_{t_{1}}^{t_{2}} I_{2}(t) d t+\int_{t_{2}}^{t_{d}} I_{3}(t) d t\right]\right]$

$$
\begin{aligned}
& =c_{h}\left[W t_{1}-\frac{D t_{1}^{2}}{2}+\left\{S-W+\frac{D}{\alpha+c}\right\}\left\{\frac{1}{\alpha+c}-\frac{e^{(\alpha+c)\left(t_{1}-t_{2}\right)}}{\alpha+c}\right\}-\frac{D\left(t_{2}-t_{1}\right)}{\alpha+c}\right. \\
& \left.+\frac{D}{\beta+c}\left\{\frac{e^{(\beta+c)\left(t_{d}-t_{2}\right)}}{\beta+c}-\frac{1}{\beta+c}-\left(t_{d}-t_{2}\right)\right\}\right]
\end{aligned}
$$

The purchase cost per cycle $(\mathrm{PC})=c_{p}(S+R)$

c) The shortage cost

$$
(\mathrm{SC})=C_{b}\left[\int_{t d}^{T}-I_{4}(t) d t\right]=\frac{c_{b} \delta D}{2}\left(T-t_{d}\right)^{2}
$$

d) Deterioration Cost $(\mathrm{DC})=c d\left[\alpha \int_{t_{1}}^{t_{2}} I_{2}(t) d t+\beta \int_{t_{2}}^{t_{d}} I_{3}(t)\right] d t$

$$
\begin{aligned}
& =c_{d} \alpha\left[\left\{S-W+\frac{D}{\alpha+c}\right\}\left\{\frac{1}{\alpha+c}-\frac{e^{(\alpha+c)\left(t_{1}-t_{2}\right)}}{\alpha+c}\right\}-\frac{D\left(t_{2}-t_{1}\right)}{\alpha+c}\right] \\
& +c_{d} \beta\left[\frac{D}{\beta+c}\left\{\frac{e^{(\beta+c)\left(t_{d}-t_{2}\right)}}{\beta+c}-\frac{1}{\beta+c}-\left(t_{d}-t_{2}\right)\right\}\right]
\end{aligned}
$$

f) Opportunity Cost (OC): $C_{l}(1-\delta) \int_{t_{d}}^{T} D d t$

$$
=C_{l}(1-\delta) D\left(T-t_{d}\right)(20)
$$

[For the values of HC, DC, SC, OC, see Appendix A.]

Therefore, total inventory cost $(X)=<$ ordering cost $>+<$ purchase cost $>+<$ holding $\cos t>+<$ shortage cost $>+<$ opportunity cost cost $>+<$ deterioration cost $>$

$$
\text { i.e., } X=C+c_{p}(S+R)+C_{h o l}+C_{\text {sho }}+D C+O C
$$

Hence, the corresponding constrained optimization problem can be written as follows:

5.1 Problem: Minimize $T C\left(t_{1}, t_{2}, t_{d}, T\right)=\frac{X}{T}$

Subject to $o \leq t_{1} \leq t_{2} \leq t_{d} \leq T$

In the proposed model, minimization of the total cost per unit time $T C\left(t_{1}, t_{2}, t_{d}, T\right)$ is the objective function. For the necessary conditions of minimization of the total cost, we set the first order partial derivatives with respect to the decision variables of $T C\left(t_{1}, t_{2}, t_{d}, T\right)$ are equal to zero.

$$
\begin{aligned}
& \frac{1}{T}\left[c_{p}\left\{D-D e^{(\alpha+c)\left(t_{2}-t_{1}\right)}-\frac{D(\alpha+c)}{\beta+c}\left\{e^{(\beta+c)\left(t_{d}-t_{2}\right)}-1\right\} e^{(\alpha+c)\left(t_{2}-t_{1}\right)}\right\}\right. \\
& +c_{h}\left[D t_{1}+\left\{-D e^{(\alpha+c)\left(t_{2}-t_{1}\right)}-\frac{D(\alpha+c)}{\beta+c}\left\{e^{(\beta+c)\left(t_{d}-t_{2}\right)}-1\right\} e^{(\alpha+c)\left(t_{2}-t_{1}\right)}\right\}\left\{\frac{1}{\alpha+c}-\frac{e^{(\alpha+c)\left(t_{1}-t_{2}\right)}}{\alpha+c}\right\}-\left\{S-W+\frac{D}{\alpha+c}\right\} e^{(\alpha+c)\left(t_{1}-t_{2}\right)}+\frac{D}{\alpha+c}\right. \\
& +c_{d} \alpha\left[\begin{array}{l}
\left.\left\{-D e^{(\alpha+c)\left(t_{2}-t_{1}\right)}-\frac{D(\alpha+c)}{\beta+c}\left\{e^{(\beta+c)\left(t_{d}-t_{2}\right)}-1\right\} e^{(\alpha+c)\left(t_{2}-t_{1}\right)}\right\}\left\{\frac{1}{\alpha+c}-\frac{e^{(\alpha+c)\left(t_{1}-t_{2}\right)}}{\alpha+c}\right\}\right]=0, \text { since } \frac{\partial C_{\text {sho }}}{\partial t_{1}}=0, \frac{\partial O C}{\partial t_{1}}=0 \\
+\left\{S-W+\frac{D}{\alpha+c}\right\}\left\{-e^{(\alpha+c)\left(t_{1}-t_{2}\right)}\right\}+\frac{D}{\alpha+c}
\end{array}\right.
\end{aligned}
$$




$$
\begin{aligned}
& \frac{1}{T}\left[c_{p}\left\{D e^{(\alpha+c)\left(t_{2}-t_{1}\right)}+\frac{D(\alpha+c)}{\beta+c}\left\{e^{(\beta+c)\left(t_{d}-t_{2}\right)}-1\right\} e^{(\alpha+c)\left(t_{2}-t_{1}\right)}-D e^{(\beta+c)\left(t_{d}-t_{2}\right)} e^{(\alpha+c)\left(t_{2}-t_{1}\right)}\right\}\right. \\
& +c_{h}\left[\begin{array}{l}
\left.\left\{D e^{(\alpha+c)\left(t_{2}-t_{1}\right)}+\frac{D(\alpha+c)}{\beta+c}\left\{e^{(\beta+c)\left(t_{d}-t_{2}\right)}-1\right\} e^{(\alpha+c)\left(t_{2}-t_{1}\right)}-D e^{(\beta+c)\left(t_{d}-t_{2}\right)} e^{(\alpha+c)\left(t_{2}-t_{1}\right)}\right\}\left\{\frac{1}{\alpha+c}-\frac{e^{(\alpha+c)\left(t_{1}-t_{2}\right)}}{\alpha+c}\right\}\right] \\
+\left\{S-W+\frac{D}{\alpha+c}\right\} e^{(\alpha+c)\left(t_{1}-t_{2}\right)}-\frac{D}{\alpha+c}+\frac{D}{\beta+c}\left\{1-e^{(\beta+c)\left(t_{d}-t_{2}\right)}\right\}
\end{array}\right] \\
& +c_{d} \alpha\left\{D e^{(\alpha+c)\left(t_{2}-t_{1}\right)}+\frac{D(\alpha+c)}{\beta+c}\left\{e^{(\beta+c)\left(t_{d}-t_{2}\right)}-1\right\} e^{(\alpha+c)\left(t_{2}-t_{1}\right)}-D e^{(\beta+c)\left(t_{d}-t_{2}\right)} e^{(\alpha+c)\left(t_{2}-t_{1}\right)}\right\}\left\{\frac{1}{\alpha+c}-\frac{e^{(\alpha+c)\left(t_{1}-t_{2}\right)}}{\alpha+c}\right\}+ \\
& {\left[\left\{S-W+\frac{D}{\alpha+c}\right\} e^{(\alpha+c)\left(t_{1}-t_{2}\right)}-\frac{D}{\alpha+c}\right]+c_{d} \beta\left[\frac{D}{\beta+c}\left\{1-e^{(\beta+c)\left(t_{d}-t_{2}\right)}\right\}\right]=0} \\
& , \operatorname{since} \frac{\partial R}{\partial t_{2}}=0 \text { and } \frac{\partial C_{s h o}}{\partial t_{2}}=0 \text { and } \frac{\partial O C}{\partial t_{2}}=0 \\
& \frac{1}{T}\left[c_{p}\left\{D e^{(\beta+c)\left(t_{d}-t_{2}\right)} e^{(\alpha+c)\left(t_{2}-t_{1}\right)}-\delta D\right\}+c_{h}\left[\frac{D}{\beta+c}\left\{e^{(\beta+c)\left(t_{d}-t_{2}\right)}-1\right\}\right]-c_{b} \delta D\left(T-t_{d}\right)+\right. \\
& c_{d} \alpha\left[\left\{D e^{(\beta+c)\left(t_{d}-t_{2}\right)} e^{(\alpha+c)\left(t_{2}-t_{1}\right)}\right\}\left\{\frac{1}{\alpha+c}-\frac{e^{(\alpha+c)\left(t_{1}-t_{2}\right)}}{\alpha+c}\right\}\right]-c_{d} \beta\left[\frac{D}{\beta+c}\left\{1-e^{(\beta+c)\left(t_{d}-t_{2}\right)}\right\}\right]-c_{l}(1-\delta) D=0 \\
& \frac{1}{T}\left[c_{p} \delta D+c_{b} \delta D\left(T-t_{d}\right)+c_{l}(1-\delta) D\right]-\frac{1}{T^{2}}\left[C+c_{p}(S+R)+c_{h}\left[W t_{1}-\frac{D t_{1}^{2}}{2}+\left\{S-W+\frac{D}{\alpha+c}\right\}\left\{\frac{1}{\alpha+c}-\frac{e^{(\alpha+c)\left(t_{1}-t_{2}\right)}}{\alpha+c}\right\}\right.\right. \\
& \left.-\frac{D\left(t_{2}-t_{1}\right)}{\alpha+c}+\frac{D}{\beta+c}\left\{\frac{e^{(\beta+c)\left(t_{d}-t_{2}\right)}}{\beta+c}-\frac{1}{\beta+c}-\left(t_{d}-t_{2}\right)\right\}\right]+\frac{c_{b} \delta D}{2}\left(T-t_{d}\right)^{2}+c_{d} \alpha\left[\left\{S-W+\frac{D}{\alpha+c}\right\}\left\{\frac{1}{\alpha+c}-\frac{e^{(\alpha+c)\left(t_{1}-t_{2}\right)}}{\alpha+c}\right\}\right. \\
& \left.\left.-\frac{D\left(t_{2}-t_{1}\right)}{\alpha+c}\right]+c_{d} \beta\left[\frac{D}{\beta+c}\left\{\frac{e^{(\beta+c)\left(t_{d}-t_{2}\right)}}{\beta+c}-\frac{1}{\beta+c}-\left(t_{d}-t_{2}\right)\right\}\right]+C_{l}(1-\delta) D\left(T-t_{d}\right)\right]=0
\end{aligned}
$$

Now to solve the objective function with respect to Eqs. (23-26) constraints we use the fmincon function of MATLAB. This gives the following results after taking initial values $x_{0}=[1,1.0777,1.1,25.555759]$ the value of the objective function is: 1543.08394470987 .

The above mention problems can also be solved by using the well-known generalized reduced gradient (GRG) method and the following algorithm below.

\subsection{Solution Procedure}

We have solved the above mentioned problem using the following algorithm:

\section{Algorithms: for solving above Problem}

Step 1: Input the value of all required parameters of the proposed inventory model.

Step 2: Solve the above discussed constrained optimization Problem and store the optimal value of the variables $T C^{*}, S^{*}, R^{*}, t_{1}^{*}, t_{2}^{*}, t_{d}^{*}$ and $T^{*}$

Step 3: Stop

\subsection{Numerical Illustrations}

To illustrate the developed model, a numerical example is presented below with the following values of different parameters has been considered.

Let us consider the following values of different parameters as follows: 
$c_{o}=\$ 200 /$ order $; a=120 ; b=0.5 ; p=15 ; c=0.4 ; c_{p}=10$ per unit per unit time, $c_{h}=4$ per unit per unit time, $c_{b}=10$ per unit per unit time, $w=200 ; c_{l}=11$ per unit per unit time, $\alpha=0.06, \beta=0.2, \delta=0.7$

The parameter values considered here are realistic, thought these values are not taken from any case study of an existing inventory system. The computational work has been done on a PC with Intel dual core $2.5 \mathrm{GHz}$ Processor. According to the proposed algorithm, the optimal solution is obtained with the help of GRG method. The optimum values of $S^{*}, R^{*}, t_{1}^{*}, t_{2}^{*}, t_{d}^{*}$ and $T^{*}$ along with minimum average cost are displayed in Table 1.

\section{Table 1}

Optimal values of different variables

\begin{tabular}{cc}
\hline Decision Variables & Values \\
\hline $\boldsymbol{T C}^{*}$ & 1539.217 \\
$\mathbf{S}^{*}$ & 247.8310 \\
$\mathbf{R}^{*}$ & 38.04668 \\
$\mathbf{t}^{*}{ }^{*}$ & 1.777778 \\
$\boldsymbol{T}^{*}$ & 2.649232 \\
$\boldsymbol{t}^{*}{ }^{*}$ & 2.166095 \\
$\boldsymbol{t}_{\boldsymbol{d}}{ }^{*}$ & 2.166099 \\
\hline
\end{tabular}

\subsection{Convexity of cost function}
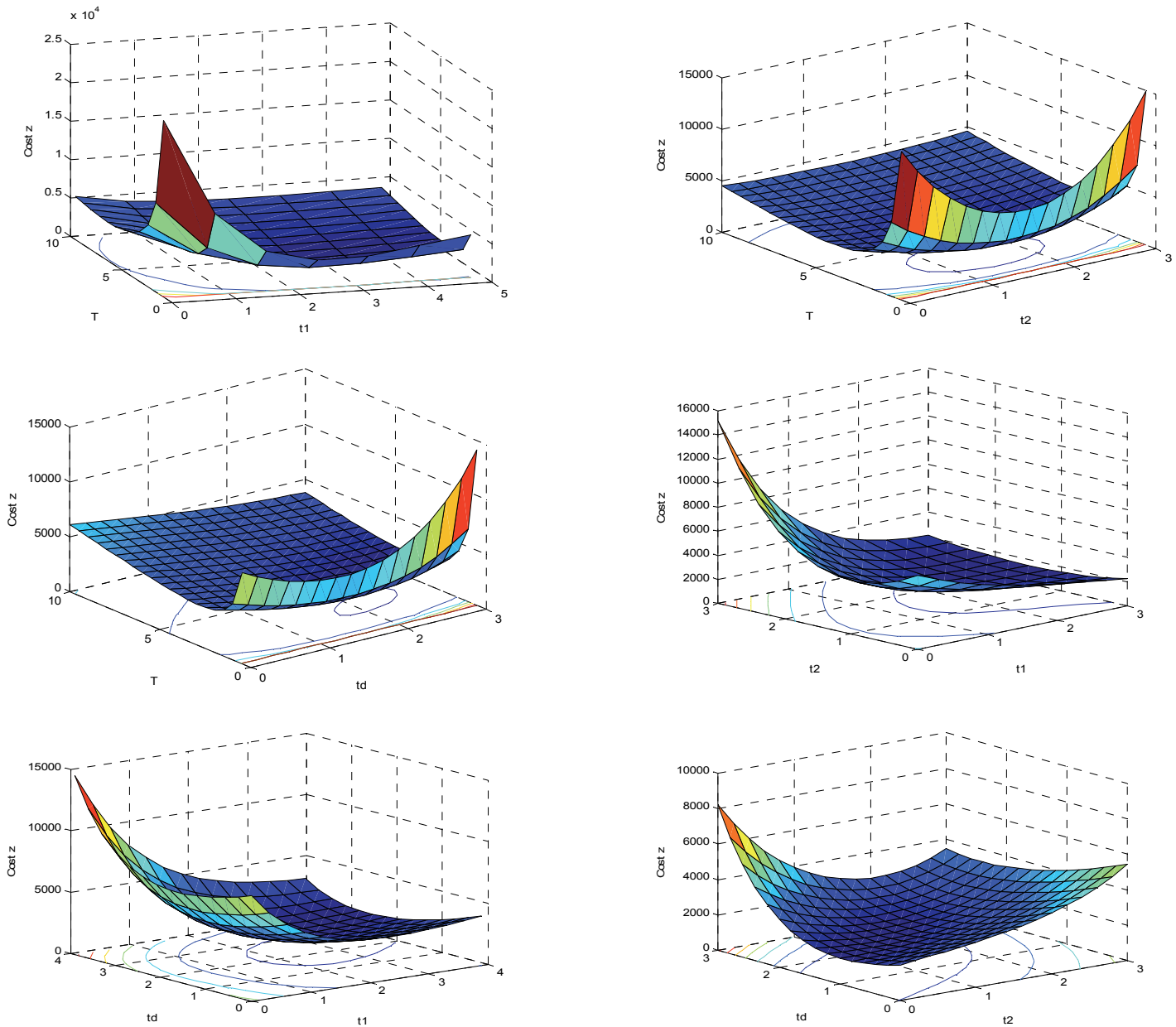

Fig. 2. Convexity of cost function with respect to different decision variables 


\section{Sensitivity Analysis}

The above numerical example is used to study the effect of an under or over estimation of the inventory system parameters on the optimal values of the initial stock level, highest shortage level, and cycle length, along with the minimum total cost of the system. The percentage changes in the above mentioned optimal values are taken as measures of sensitivity.

Table 2

Sensitivity analysis with respect to different parameters

\begin{tabular}{|c|c|c|c|c|c|c|c|c|}
\hline \multirow[b]{2}{*}{ Parameter } & \multirow[b]{2}{*}{$\begin{array}{l}\% \text { changes of } \\
\text { parameters }\end{array}$} & \multirow[b]{2}{*}{$\begin{array}{c}\% \text { changes in } \\
T C^{*}\end{array}$} & \multicolumn{6}{|c|}{$\%$ changes in } \\
\hline & & & $S^{*}$ & $R^{*}$ & $t_{1}^{*}$ & $T^{*}$ & $t_{2}^{*}$ & $t_{d}^{*}$ \\
\hline \multirow{4}{*}{$\alpha$} & -20 & 0.004 & 0.32 & 0.02 & 0 & -0.15 & -17.93 & -0.19 \\
\hline & -10 & 2.36 & -19.3 & 9.53 & 0 & -12.92 & -17.93 & -17.93 \\
\hline & 10 & 0 & 0.32 & 0.02 & 0 & -0.15 & -17.93 & -0.19 \\
\hline & 20 & 0.03 & -0.22 & 0.11 & 0 & -0.16 & -0.22 & -0.22 \\
\hline \multirow{4}{*}{$\delta$} & -20 & -0.32 & 0.08 & -5.44 & 0 & 3.01 & -17.93 & -0.38 \\
\hline & -10 & -0.15 & -0.1 & -2.66 & 0 & 1.41 & -0.09 & -0.09 \\
\hline & 10 & 0.13 & 0.41 & 2.58 & 0 & -1.32 & -17.93 & -0.11 \\
\hline & 20 & 0.23 & 0.48 & 5.06 & 0 & -2.32 & -17.93 & -0.05 \\
\hline \multirow{4}{*}{$\beta$} & -20 & -0.14 & 1.66 & -0.59 & 0 & 0.74 & -17.93 & 1.04 \\
\hline & -10 & 0 & 0 & 0 & 0 & 0 & 0 & 0 \\
\hline & 10 & 0 & 0 & 0 & 0 & 0 & 0 & 0 \\
\hline & 20 & 0 & 0 & 0 & 0 & 0 & 0 & 0 \\
\hline \multirow{4}{*}{$c_{O}$} & -20 & -0.98 & -0.4 & -3.98 & 0 & -1.36 & -17.93 & -0.77 \\
\hline & -10 & -0.49 & -0.04 & -1.98 & 0 & -0.75 & -17.93 & -0.48 \\
\hline & 10 & 0.49 & 0.68 & 2 & 0 & 0.45 & -17.93 & 0.1 \\
\hline & 20 & 0.98 & 1.03 & 3.97 & 0 & 1.04 & -17.93 & 0.39 \\
\hline \multirow{4}{*}{$p$} & -20 & 1.05 & 0.37 & 0.18 & -1.32 & -1.38 & -19.01 & -1.43 \\
\hline & -10 & 0.52 & 0.02 & 0.08 & -0.66 & -0.62 & -0.63 & -0.63 \\
\hline & 10 & -0.52 & -0.02 & -0.08 & 0.67 & 0.63 & 0.64 & 0.64 \\
\hline & 20 & -1.04 & -0.05 & -0.16 & 1.35 & 1.27 & 1.29 & 1.29 \\
\hline \multirow{4}{*}{$c_{b}$} & -20 & -0.54 & -0.39 & 22.26 & 0 & 3.79 & -0.33 & -0.33 \\
\hline & -10 & -0.24 & 0.14 & 10.02 & 0 & 1.56 & -17.93 & -0.33 \\
\hline & 10 & 0.21 & 0.47 & -8.31 & 0 & -1.57 & -17.93 & -0.06 \\
\hline & 20 & 0.39 & 0.28 & -15.36 & 0 & -2.61 & 0.24 & 0.24 \\
\hline \multirow{4}{*}{$c_{h}$} & -20 & -3.72 & -0.97 & -15.05 & 0 & -3.43 & -0.83 & -0.83 \\
\hline & -10 & -1.85 & -0.45 & -7.47 & 0 & -1.68 & -0.39 & -0.39 \\
\hline & 10 & 1.79 & 1.05 & 7.24 & 0 & 1.65 & -17.93 & 0.4 \\
\hline & 20 & 3.55 & 1.72 & 14.35 & 0 & 3.38 & -17.93 & 0.94 \\
\hline \multirow{4}{*}{$c_{p}$} & -20 & -11.31 & -19.3 & -4.34 & 0 & -15.45 & -17.93 & -17.93 \\
\hline & -10 & -7.03 & 1.29 & -7.75 & 0 & -0.52 & 1.09 & 1.09 \\
\hline & 10 & 6.99 & -1.19 & 7.58 & 0 & 0.55 & -1.02 & -1.02 \\
\hline & 20 & 13.94 & -2.29 & 15.01 & 0 & 1.13 & -1.97 & -1.97 \\
\hline \multirow{4}{*}{$a$} & -20 & -13.91 & -0.35 & -2.12 & 21.62 & 20.05 & -0.18 & 20.28 \\
\hline & -10 & -6.95 & -0.01 & -1.05 & 9.76 & 8.98 & -9.92 & 9.06 \\
\hline & 10 & 6.96 & 0.65 & 1.08 & -8.16 & -7.8 & -24.63 & -7.94 \\
\hline & 20 & 13.91 & 0.99 & 2.15 & -15.09 & -14.3 & -30.32 & -14.53 \\
\hline \multirow{4}{*}{$b$} & -20 & 1.05 & 0.37 & 0.18 & -1.32 & -1.38 & -19.01 & -1.43 \\
\hline & -10 & 0.52 & 0.02 & 0.08 & -0.66 & -0.62 & -0.63 & -0.63 \\
\hline & 10 & -0.52 & -0.02 & -0.08 & 0.67 & 0.63 & 0.64 & 0.64 \\
\hline & 20 & -1.04 & -0.05 & -0.16 & 1.35 & 1.27 & 1.29 & 1.29 \\
\hline \multirow{4}{*}{$\mathrm{c}$} & -20 & -0.22 & 1.79 & -0.87 & 0 & 1.34 & 1.83 & 1.83 \\
\hline & -10 & -0.1 & 0.86 & -0.42 & 0 & 0.64 & 0.87 & 0.87 \\
\hline & 10 & 2.36 & -19.3 & 9.53 & 0 & -12.92 & -17.93 & -17.93 \\
\hline & 20 & 0.18 & -1.51 & 0.74 & 0 & -1.11 & -1.52 & -1.52 \\
\hline \multirow{4}{*}{$c_{l}$} & -20 & -0.93 & -0.36 & 15.73 & 0 & 2.26 & -17.93 & -0.74 \\
\hline & -10 & -0.45 & -0.33 & 7.92 & 0 & 1.22 & -0.28 & -0.28 \\
\hline & 10 & 0.43 & 0.63 & -8.02 & 0 & -1.41 & -17.93 & 0.06 \\
\hline & 20 & 0.82 & 0.92 & -16.18 & 0 & -2.71 & -17.93 & 0.3 \\
\hline & -20 & -3.15 & -18.12 & -12.74 & -20 & -17.43 & -34.34 & -18.48 \\
\hline$W$ & -10 & -1.63 & -8.94 & -6.6 & -10 & -8.86 & -26.13 & -9.36 \\
\hline$W$ & 10 & 1.72 & 9.31 & 6.97 & 10 & 8.84 & 9.25 & 9.25 \\
\hline & 20 & 6.03 & -3.16 & 24.41 & 20 & 3.21 & -1.51 & -1.51 \\
\hline & -20 & -0.002 & 0.02 & -0.01 & 0 & 0.02 & 0.02 & 0.02 \\
\hline & -10 & .0018 & 0.35 & 0.01 & 0 & -0.13 & -17.93 & -0.16 \\
\hline$c_{d}$ & 10 & 0.001 & -0.01 & 0.01 & 0 & -0.01 & -0.01 & -0.01 \\
\hline & 20 & 0.002 & -0.02 & 0.01 & 0 & -0.02 & -0.02 & -0.02 \\
\hline
\end{tabular}


The analysis is carried out by changing (increasing and decreasing) the parameters between - $20 \%$ and $+20 \%$. The results are obtained by changing one parameter at a time and keeping the other parameters at their original values. The result of this analysis is given in Table 2 below. Form Table 2, the following observations are made:

(i) The average cost is highly sensitive with respect to the demand parameters $a$ (location parameter) and purchase $\operatorname{cost} c_{p}$. The average profit is moderately sensitive with respect to other parameters.

(ii) Cycle length of the system is insensitive with respect to $\beta$. It is moderately sensitive with respect to other parameters.

(iii) The highest shortage level is insensitive with respect to $\beta$ and highly sensitive with respect to 'w', 'c $\mathrm{c}_{\mathrm{b}}$ ' and 'a'.

(iv) The highest on-hand stock-level $S$ is insensitive with respect to the parameter $\beta$ and it is moderately sensitive with respect to the rest of the parameters.

(v) The initial deterioration level is insensitive with respect to $\alpha, c_{l}, c_{o}, \delta, \beta, c_{b}, c_{h}, \mathrm{c}$, $c_{p}$, and $c_{d}$ highly sensitive with respect to ' $\mathrm{a}$ ' and ' $\mathrm{W}$ ' and moderately sensitive with respect to the rest of the parameters.

\section{Concluding Remarks}

In this research, an inventory model was described according by considering price, stock dependent demand, two different constant deteriorations, and partially backlogged shortages. Initially demand function was dependent on price and when deterioration appears then the demand was dependent on both stock and price of the item and finally when shortage appears the demand depends only on price of the product. In this paper, the deterioration has been considered as non-instantaneous i.e., when the item stock in retailer's house after some time deterioration will start. This is because of two constant deteriorations along with customers' demand shortage appears and it is partially backlogged. The corresponding inventory problem constitutes a nonlinear constraint optimization problem. We have solved this problem with the help of MATLAB software and validated it by sketching some convex graphs of the cost function with respect to the decisions variables and also making a sensitivity table to show the validate range for the parameters which makes the cost function more perfection.

\section{References}

Abad, P. L. (1996). Optimal pricing and lot-sizing under conditions of perishability and partial backordering. Management Science, 42(8), 1093-1104.

Avinadav, T., Herbon, A., \& Spiegel, U. (2013). Optimal inventory policy for a perishable item with demand function sensitive to price and time. International Journal of Production Economics, 144(2), 497-506.

Taleizadeh, A. A., Stojkovska, I., \& Pentico, D. W. (2015). An economic order quantity model with partial backordering and incremental discount. Computers \& Industrial Engineering, 82, 21-32.

Bhunia, A., \& Shaikh, A. (2011). A deterministic model for deteriorating items with displayed inventory level dependent demand rate incorporating marketing decisions with transportation cost. International Journal of Industrial Engineering Computations, 2(3), 547-562.

Bhunia, A., Shaikh, A., Maiti, A., \& Maiti, M. (2013). A two warehouse deterministic inventory model for deteriorating items with a linear trend in time dependent demand over finite time horizon by elitist real-coded genetic algorithm. International Journal of Industrial Engineering Computations, 4(2), 241-258.

Gilding, B. H. (2014). Inflation and the optimal inventory replenishment schedule within a finite planning horizon. European Journal of Operational Research, 234(3), 683-693. 
Bhunia, A., \& Shaikh, A. (2014). A deterministic inventory model for deteriorating items with selling price dependent demand and three-parameter Weibull distributed deterioration. International Journal of Industrial Engineering Computations, 5(3), 497-510.

Bhunia, A. K., Mahato, S. K., Shaikh, A. A., \& Jaggi, C. K. (2014). A deteriorating inventory model with displayed stock-level-dependent demand and partially backlogged shortages with all unit discount facilities via particle swarm optimisation. International Journal of Systems Science: Operations \& Logistics, 1(3), 164-180.

Bhunia, A., Shaikh, A., Pareek, S., \& Dhaka, V. (2015). A memo on stock model with partial backlogging under delay in payments. Uncertain Supply Chain Management, 3(1), 11-20.

Bhunia, A. K., \& Shaikh, A. A. (2015). An application of PSO in a two-warehouse inventory model for deteriorating item under permissible delay in payment with different inventory policies. Applied Mathematics and Computation, 256, 831-850.

Bhunia, A. K., \& Shaikh, A. A. (2016). Investigation of two-warehouse inventory problems in interval environment under inflation via particle swarm optimization. Mathematical and Computer Modelling of Dynamical Systems, 22(2), 160-179.

Covert, R. P., \& Philip, G. C. (1973). An EOQ model for items with Weibull distribution deterioration. AIIE Transactions, 5(4), 323-326.

Datta, T., \& Pal, A. (1990). A note on an inventory-level-dependent demand rate. Journal of the

Operational Research Society, 41, 971-975.

Ghare, P.M., \& Schrader, G.F. (1963). An inventory model for exponentially deteriorating items. Journal of Industrial Engineering 14, 238-243.

Giri, B. C., Jalan, A. K., \& Chaudhuri, K. S. (2003). Economic order quantity model with Weibull deterioration distribution, shortage and ramp-type demand. International Journal of Systems Science, 34(4), 237-243.

Goyal, S. K., \& Gunasekaran, A. (1995). An integrated production-inventory-marketing model for deteriorating items. Computers \& Industrial Engineering, 28(4), 755-762.

Gupta, R., \& Vrat, P. (1986). Inventory model for stock-dependent consumption rate. Opsearch, 23(1), 19-24.

Harris, F. W. (1913). How Many Parts to Make at Once, Factory. The Magazine of Management, 10, $135-136$.

Lee, Y. P., \& Dye, C. Y. (2012). An inventory model for deteriorating items under stock-dependent demand and controllable deterioration rate. Computers \& Industrial Engineering, 63(2), 474-482.

Levin, R. I., McLaughlin, C. P., Lamone, R. P., \& Kottas, J. F. (1972). Productions/operations management: contemporary policy for managing operating systems. New York: McGraw-Hill.

Mandal, B. N., \& Phaujdar, S. (1989). An inventory model for deteriorating items and stock-dependent consumption rate. Journal of the operational Research Society, 40, 483-488.

Manna, S. K., \& Chaudhuri, K. S. (2006). An EOQ model with ramp type demand rate, time dependent deterioration rate, unit production cost and shortages. European Journal of Operational Research, 171(2), 557-566.

Min, J., Zhou, Y. W., Liu, G. Q., \& Wang, S. D. (2012). An EPQ model for deteriorating items with inventory-level-dependent demand and permissible delay in payments. International Journal of Systems Science, 43(6), 1039-1053.

Kurdi, M. (2015). A structural optimization framework for multidisciplinary design. Journal of Optimization, 1-14.

El-Hadidy, M. A. A. (2016). On maximum discounted effort reward search problem. Asia-Pacific Journal of Operational Research, 33(03), 1650019.

Padmanabhan, G., \& Vrat, P. (1995). EOQ models for perishable items under stock dependent selling rate. European Journal of Operational Research, 86(2), 281-292.

Ray, J., \& Chaudhuri, K. S. (1997). An EOQ model with stock-dependent demand, shortage, inflation and time discounting. International Journal of Production Economics, 53(2), 171-180.

Ray, J., Goswami, A., \& Chaudhuri, K. S. (1998). On an inventory model with two levels of storage and stock-dependent demand rate. International Journal of Systems Science, 29(3), 249-254. 
Pal, S., Goswami, A., \& Chaudhuri, K. S. (1993). A deterministic inventory model for deteriorating items with stock-dependent demand rate. International Journal of Production Economics, 32(3), 291-299. Pal, P., Bhunia, A. K., \& Goyal, S. K. (2007). On optimal partially integrated production and marketing policy with variable demand under flexibility and reliability considerations via Genetic Algorithm. Applied mathematics and computation, 188(1), 525-537.

Shaikh, A. A., Mashud, A. H. M., Uddin, M. S., \& Khan, M. A. A. (2017). Non-instantaneous deterioration inventory model with price and stock dependent demand for fully backlogged shortages under inflation. International Journal of Business Forecasting and Marketing Intelligence, 3(2), 152-164.

Subramanyam, E. S., \& Kumaraswamy, S. (1981). EOQ formula under varying marketing policies and conditions. AIIE Transactions, 13(4), 312-314.

Sana, S. S. (2010). Optimal selling price and lotsize with time varying deterioration and partial backlogging. Applied Mathematics and Computation, 217(1), 185-194.

Sarker, B. R., Mukherjee, S., \& Balan, C. V. (1997). An order-level lot size inventory model with inventory-level dependent demand and deterioration. International Journal of Production Economics, 48(3), 227-236.

Sarkar, B. (2012a). An EOQ model with delay in payments and time varying deterioration rate. Mathematical and Computer Modelling, 55(3), 367-377.

Sarkar, B. (2013). A production-inventory model with probabilistic deterioration in two-echelon supply chain management. Applied Mathematical Modelling, 37(5), 3138-3151. Sett, B. K., Sarkar, B., \& Goswami, A. (2012). A two-warehouse inventory model with increasing demand and time varying deterioration. Scientia Iranica, 19(6), 1969-1977.

Taleizadeh, A. A., \& Pentico, D. W. (2013). An economic order quantity model with a known price increase and partial backordering. European Journal of Operational Research, 228(3), 516-525.

Skouri, K., Konstantaras, I., Papachristos, S., \& Ganas, I. (2009). Inventory models with ramp type demand rate, partial backlogging and Weibull deterioration rate. European Journal of Operational Research, 192(1), 79-92.

Urban, T. L. (1992). Deterministic inventory models incorporating marketing decisions. Computers \& industrial engineering, 22(1), 85-93.

Wu, K.S., Ouyang, L.Y., Yang, C.T., 2006. An optimal replenishment policy for noninstantaneous deteriorating items with stock-dependent demand and partial backlogging. International Journal of Production Economics 101, 369-384.

\section{Appendix A:}

The values are

$$
\begin{aligned}
& \text { Holding Cost, } \mathrm{HC}=c_{h}\left[\int_{0}^{t_{1}} I_{1}(t) d t+\int_{t_{1}}^{t_{2}} I_{2}(t) d t+\int_{t_{2}}^{t_{d}} I_{3}(t) d t\right] \\
& =c_{h}\left[\int_{0}^{t_{1}}(W-D t) d t+\int_{t_{1}}^{t_{2}}\left[\frac{-D}{(\alpha+c)}+\left\{S-W+\frac{D}{(\alpha+c)}\right\} e^{(\alpha+c)\left(t_{1}-t\right)}\right] d t+\int_{t_{2}}^{t_{d}} \frac{D}{(\beta+c)}\left\{e^{(\beta+c)\left(t_{d}-t\right)}-1\right\} d t\right] \\
& =c_{h}\left[\int_{0}^{t_{1}}(W-D t) d t-\frac{D\left(t_{2}-t_{1}\right)}{(\alpha+c)}+\int_{t_{1}}^{t_{2}}\left[\left\{S-W+\frac{D}{(\alpha+c)}\right\}\left\{e^{(\alpha+c)\left(t_{1}-t\right)}\right\} d t+\int_{t_{2}}^{t_{d}} \frac{D}{(\beta+c)}\left\{e^{(\beta+c)\left(t_{d}-t\right)}-1\right\} d t\right]\right. \\
& =c_{h}\left[\left[W t-\frac{D t^{2}}{2}\right]_{0}^{t_{1}}-\frac{D\left(t_{2}-t_{1}\right)}{(\alpha+c)}+\left[\left\{S-W+\frac{D}{(\alpha+c)}\right\}\left\{\frac{e^{(\alpha+c)\left(t_{1}-t\right)}}{-(\alpha+c)}\right\}\right]_{t_{1}}^{t_{2}}+\frac{D}{(\beta+c)}\left[\frac{e^{(\beta+c)\left(t_{d}-t\right)}}{-(\beta+c)}-t\right]_{t_{2}}^{t_{d}}\right] \\
& =c_{h}\left[W t_{1}-\frac{D t_{1}^{2}}{2}+\left\{S-W+\frac{D}{\alpha+c}\right\}\left\{\frac{1}{\alpha+c}-\frac{e^{(\alpha+c)\left(t_{1}-t_{2}\right)}}{\alpha+c}\right\}-\frac{D\left(t_{2}-t_{1}\right)}{\alpha+c}+\frac{D}{\beta+c}\left\{\frac{e^{(\beta+c)\left(t_{d}-t_{2}\right)}}{\beta+c}-\frac{1}{\beta+c}-\left(t_{d}-t_{2}\right)\right\}\right]
\end{aligned}
$$

Now differentiating Holding cost (HC) with respect to different decision variables we get: 


$$
\begin{aligned}
& \frac{\partial H C}{\partial t_{1}}=c_{h}\left[2 t_{1} D-D t_{1}+\left\{\frac{\partial S}{\partial t_{1}}-\frac{\partial W}{\partial t_{1}}\right\}\left\{\frac{1}{\alpha+c}-\frac{e^{(\alpha+c)\left(t_{1}-t_{2}\right)}}{\alpha+c}\right\}+\left\{S-W+\frac{D}{\alpha+c}\right\}\left\{-e^{(\alpha+c)\left(t_{1}-t_{2}\right)}\right\}+\frac{D}{\alpha+c}\right. \\
& \left.+\frac{D}{\beta+c}\{0-0-0\}\right] \\
& \frac{\partial H C}{\partial t_{1}}=c_{h}\left[\begin{array}{l}
D t_{1}+\left\{D-D e^{(\alpha+c)\left(t_{2}-t_{1}\right)}-\frac{D(\alpha+c)}{\beta+c}\left\{e^{(\beta+c)\left(t_{d}-t_{2}\right)}-1\right\} e^{(\alpha+c)\left(t_{2}-t_{1}\right)}-D\right\}\left\{\frac{1}{\alpha+c}-\frac{e^{(\alpha+c)\left(t_{1}-t_{2}\right)}}{\alpha+c}\right\} \\
\left.+\left\{S-W+\frac{D}{\alpha+c}\right\}\left\{-e^{(\alpha+c)\left(t_{1}-t_{2}\right)}\right\}+\frac{D}{\alpha+c}\right]
\end{array}\right. \\
& \frac{\partial H C}{\partial t_{1}}=c_{h}\left[\begin{array}{l}
D t_{1}+\left\{-D e^{(\alpha+c)\left(t_{2}-t_{1}\right)}-\frac{D(\alpha+c)}{\beta+c}\left\{e^{(\beta+c)\left(t_{d}-t_{2}\right)}-1\right\} e^{(\alpha+c)\left(t_{2}-t_{1}\right)}\right\}\left\{\frac{1}{\alpha+c}-\frac{e^{(\alpha+c)\left(t_{1}-t_{2}\right)}}{\alpha+c}\right\} \\
-\left\{S-W+\frac{D}{\alpha+c}\right\} e^{(\alpha+c)\left(t_{1}-t_{2}\right)}+\frac{D}{\alpha+c}
\end{array}\right] \\
& \frac{\partial H C}{\partial t_{2}}=c_{h}\left[\begin{array}{l}
\left\{D e^{(\alpha+c)\left(t_{2}-t_{1}\right)}+\frac{D(\alpha+c)}{\beta+c}\left\{e^{(\beta+c)\left(t_{d}-t_{2}\right)}-1\right\} e^{(\alpha+c)\left(t_{2}-t_{1}\right)}-D e^{(\beta+c)\left(t_{d}-t_{2}\right)} e^{(\alpha+c)\left(t_{2}-t_{1}\right)}\right\}\left\{\frac{1}{\alpha+c}-\frac{e^{(\alpha+c)\left(t_{1}-t_{2}\right)}}{\alpha+c}\right\} \\
+\left\{S-W+\frac{D}{\alpha+c}\right\} e^{(\alpha+c)\left(t_{1}-t_{2}\right)}-\frac{D}{\alpha+c}+\frac{D}{\beta+c}\left\{1-e^{(\beta+c)\left(t_{d}-t_{2}\right)}\right\}
\end{array}\right] \\
& \frac{\partial H C}{\partial t_{d}}=c_{h}\left[\frac{D}{\beta+c}\left\{e^{(\beta+c)\left(t_{d}-t_{2}\right)}-1\right\}\right] \\
& \frac{\partial H C}{\partial T}=0
\end{aligned}
$$

Shortage Cost, $\mathrm{SC}=c_{b} \int_{t_{d}}^{T}-I_{4}(t) d t$$$
=c_{b} \int_{t_{d}}^{T}-\left[\delta D\left(t_{d}-t\right)\right] d t
$$$$
=c_{b} \delta D \int_{t_{d}}^{T}\left(t-t_{d}\right) d t
$$$$
=\frac{c_{b} \delta D}{2}\left[\left(t-t_{d}\right)^{2}\right]_{t_{d}}^{T}
$$$$
=\frac{c_{b} \delta D}{2}\left(T-t_{d}\right)^{2}
$$

Shortage $\cos t, S C=\frac{c_{b} \delta D}{2}\left(T-t_{d}\right)^{2}$

Now differentiating Shortage cost (SC) with respect to different decision variables we get:

$\frac{\partial S C}{\partial t_{1}}=0, \frac{\partial S C}{\partial t_{2}}=0, \frac{\partial S C}{\partial t_{d}}=-c_{b} \delta D\left(T-t_{d}\right), \frac{\partial S C}{\partial T}=c_{b} \delta D\left(T-t_{d}\right)$

Deterioration Cost, $\mathrm{DC}=c d\left[\alpha \int_{t_{1}}^{t_{2}} I_{2}(t) d t+\beta \int_{t_{2}}^{t_{d}} I_{3}(t)\right] d t$

$$
\begin{aligned}
& =c d\left[\alpha \int_{t_{1}}^{t_{2}}\left[\frac{-D}{(\alpha+c)}+\left\{S-W+\frac{D}{(\alpha+c)}\right\} e^{(\alpha+c)\left(t_{1}-t\right)}\right] d t+\beta \int \frac{D}{t_{d}} \frac{D}{(\beta+c)}\left\{e^{(\beta+c)\left(t_{d}-t\right)}-1\right\}\right] d t \\
& =c d\left[\alpha \int_{t_{1}}^{t_{2}}\left[\left\{S-W+\frac{D}{(\alpha+c)}\right\}\left\{e^{(\alpha+c)\left(t_{1}-t\right)}\right\}-\frac{D\left(t_{2}-t_{1}\right)}{\alpha+c}\right] d t+\beta \int \frac{D}{t_{2}} \frac{D}{(\beta+c)}\left\{e^{(\beta+c)\left(t_{d}-t\right)}-1\right\}\right] d t
\end{aligned}
$$




$$
\begin{aligned}
& =c d\left[\alpha\left[\left\{S-W+\frac{D}{(\alpha+c)}\right\}\left\{\frac{e^{(\alpha+c)\left(t_{1}-t\right)}}{-(\alpha+c)}\right\}_{t_{1}}^{t_{2}}-\frac{D\left(t_{2}-t_{1}\right)}{\alpha+c}\right]+\frac{\beta D}{(\beta+c)}\left[\frac{e^{(\beta+c)\left(t_{d}-t\right)}}{-(\beta+c)}-t\right]_{t_{2}}^{t_{d}}\right] \\
& =c_{d} \alpha\left[\left\{S-W+\frac{D}{\alpha+c}\right\}\left\{\frac{1}{\alpha+c}-\frac{e^{(\alpha+c)\left(t_{1}-t_{2}\right)}}{\alpha+c}\right\}-\frac{D\left(t_{2}-t_{1}\right)}{\alpha+c}\right]+c_{d} \beta\left[\frac{D}{\beta+c}\left\{\frac{e^{(\beta+c)\left(t_{d}-t_{2}\right)}}{\beta+c}-\frac{1}{\beta+c}-\left(t_{d}-t_{2}\right)\right\}\right]
\end{aligned}
$$

Now differentiating Deterioration cost (DC) with respect to different decision variables we get:

$$
\begin{aligned}
& \frac{\partial D C}{\partial t_{1}}=c_{d} \alpha\left[\left\{-D e^{(\alpha+c)\left(t_{2}-t_{1}\right)}-\frac{D(\alpha+c)}{\beta+c}\left\{e^{(\beta+c)\left(t_{d}-t_{2}\right)}-1\right\} e^{(\alpha+c)\left(t_{2}-t_{1}\right)}\right\}\left\{\frac{1}{\alpha+c}-\frac{e^{(\alpha+c)\left(t_{1}-t_{2}\right)}}{\alpha+c}\right\}+\left\{S-W+\frac{D}{\alpha+c}\right\}\left\{-e^{(\alpha+c)\left(t_{1}-t_{2}\right)}\right\}+\frac{D}{\alpha+c}\right] \\
& \frac{\partial D C}{\partial t_{2}}=c_{d} \alpha\left\{D e^{(\alpha+c)\left(t_{2}-t_{1}\right)}+\frac{D(\alpha+c)}{\beta+c}\left\{e^{(\beta+c)\left(t_{d}-t_{2}\right)}-1\right\} e^{(\alpha+c)\left(t_{2}-t_{1}\right)}-D e^{(\beta+c)\left(t_{d}-t_{2}\right)} e^{(\alpha+c)\left(t_{2}-t_{1}\right)}\right\}\left\{\frac{1}{\alpha+c}-\frac{e^{(\alpha+c)\left(t_{1}-t_{2}\right)}}{\alpha+c}\right\} \\
& {\left[\left\{S-W+\frac{D}{\alpha+c}\right\} e^{(\alpha+c)\left(t_{1}-t_{2}\right)}-\frac{D}{\alpha+c}\right]+c_{d} \beta\left[\frac{D}{\beta+c}\left\{1-e^{(\beta+c)\left(t_{d}-t_{2}\right)}\right\}\right]} \\
& \frac{\partial D C}{\partial t_{d}}=c_{d} \alpha\left[\left\{D e^{(\beta+c)\left(t_{d}-t_{2}\right)} e^{(\alpha+c)\left(t_{2}-t_{1}\right)}\right\}\left\{\frac{1}{\alpha+c}-\frac{e^{(\alpha+c)\left(t_{1}-t_{2}\right)}}{\alpha+c}\right\}\right]-c_{d} \beta\left[\frac{D}{\beta+c}\left\{1-e^{(\beta+c)\left(t_{d}-t_{2}\right)}\right\}\right] \\
& \frac{\partial D C}{\partial T}=0
\end{aligned}
$$$$
\text { Opportunity Cost, } \mathrm{OC}=C_{l}(1-\delta) \int_{t_{l}}^{T} D d t
$$$$
\begin{aligned}
& =C_{l}(1-\delta)[D t]_{t_{d}}^{T} \\
& =C_{l}(1-\delta) D\left(T-t_{d}\right)
\end{aligned}
$$

Now differentiating Opportunity cost (OC) with respect to different decision variables we get:

$$
\begin{aligned}
& \frac{\partial O C}{\partial t_{1}}=0, \frac{\partial O C}{\partial t_{2}}=0, \frac{\partial O C}{\partial t_{d}}=-c_{l}(1-\delta) D, \frac{\partial O C}{\partial T}=c_{l}(1-\delta) D \\
& S=D t_{1}-\frac{D}{\alpha+c}+\frac{D}{\alpha+c} e^{(\alpha+c)\left(t_{2}-t_{1}\right)}+\frac{D}{\beta+c}\left\{e^{(\beta+c)\left(t_{d}-t_{2}\right)}-1\right\} e^{(\alpha+c)\left(t_{2}-t_{1}\right)} \\
& \therefore \frac{\partial S}{\partial t_{1}}=D-D e^{(\alpha+c)\left(t_{2}-t_{1}\right)}-\frac{D(\alpha+c)}{\beta+c}\left\{e^{(\beta+c)\left(t_{d}-t_{2}\right)}-1\right\} e^{(\alpha+c)\left(t_{2}-t_{1}\right)} \\
& \therefore \frac{\partial S}{\partial t_{2}}=D e^{(\alpha+c)\left(t_{2}-t_{1}\right)}+\frac{D(\alpha+c)}{\beta+c}\left\{e^{(\beta+c)\left(t_{d}-t_{2}\right)}-1\right\} e^{(\alpha+c)\left(t_{2}-t_{1}\right)}-D e^{(\beta+c)\left(t_{d}-t_{2}\right)} e^{(\alpha+c)\left(t_{2}-t_{1}\right)} \\
& \therefore \frac{\partial S}{\partial t_{d}}=D e^{(\beta+c)\left(t_{d}-t_{2}\right)} e^{(\alpha+c)\left(t_{2}-t_{1}\right)} \\
& \therefore \frac{\partial S}{\partial T}=0 \\
& R=\delta D\left(T-t_{d}\right) \\
& \frac{\partial R}{\partial t_{1}}=0, \frac{\partial R}{\partial t_{2}}=0, \frac{\partial R}{\partial t_{d}}=-\delta D, \frac{\partial R}{\partial T}=\delta D
\end{aligned}
$$

\section{Appendix-B}

$$
\begin{aligned}
& X=C+c_{p}(S+R)+C_{h o l}+C_{s h o}+D C+O C \\
& \frac{\partial X}{\partial t_{1}}=c_{p}\left(\frac{\partial s}{\partial t_{1}}+\frac{\partial R}{\partial t_{1}}\right)+\frac{\partial C_{h o l}}{\partial t_{1}}+\frac{\partial C_{\text {shoo }}}{\partial t_{1}}+\frac{\partial D C}{\partial t_{1}}+\frac{\partial O C}{\partial t_{1}} \quad \frac{\partial T C}{\partial t_{1}}=\frac{1}{T}\left[c_{p}\left(\frac{\partial s}{\partial t_{1}}+\frac{\partial R}{\partial t_{1}}\right)+\frac{\partial C_{h o l}}{\partial t_{1}}+\frac{\partial C_{s h o o}}{\partial t_{1}}+\frac{\partial D C}{\partial t_{1}}+\frac{\partial O C}{\partial t_{1}}\right]
\end{aligned}
$$


Now, $\frac{\partial T c}{\partial t_{1}}=0$

$$
\begin{aligned}
& \frac{1}{T}\left[c_{p}\left(\frac{\partial s}{\partial t_{1}}+\frac{\partial R}{\partial t_{1}}\right)+\frac{\partial C_{h o l}}{\partial t_{1}}+\frac{\partial C_{s h o}}{\partial t_{1}}+\frac{\partial D C}{\partial t_{1}}+\frac{\partial O C}{\partial t_{1}}\right]=0 \\
& \Rightarrow \frac{1}{T}\left[c_{p}\left\{D-D e^{(\alpha+c)\left(t_{2}-t_{1}\right)}-\frac{D(\alpha+c)}{\beta+c}\left\{e^{(\beta+c)\left(t_{d}-t_{2}\right)}-1\right\} e^{(\alpha+c)\left(t_{2}-t_{1}\right)}\right\}+c_{h}\left[D t_{1}\right.\right. \\
&+\left\{-D e^{(\alpha+c)\left(t_{2}-t_{1}\right)}-\frac{D(\alpha+c)}{\beta+c}\left\{e^{(\beta+c)\left(t_{d}-t_{2}\right)}-1\right\} e^{(\alpha+c)\left(t_{2}-t_{1}\right)}\right\} \\
&\left.\left\{\frac{1}{\alpha+c}-\frac{e^{(\alpha+c)\left(t_{1}-t_{2}\right)}}{\alpha+c}\right\}-\left\{S-W+\frac{D}{\alpha+c}\right\} e^{(\alpha+c)\left(t_{1}-t_{2}\right)}+\frac{D}{\alpha+c}\right]+ \\
& c_{d} \alpha\left[\left\{-D e^{(\alpha+c)\left(t_{2}-t_{1}\right)}-\frac{D(\alpha+c)}{\beta+c}\left\{e^{(\beta+c)\left(t_{d}-t_{2}\right)}-1\right\} e^{(\alpha+c)\left(t_{2}-t_{1}\right)}\right\}\left\{\frac{1}{\alpha+c}-\frac{e^{(\alpha+c)\left(t_{1}-t_{2}\right)}}{\alpha+c}\right\}\right]=0 \\
&+\left\{S-W+\frac{D}{\alpha+c}\right\}\left\{-e^{(\alpha+c)\left(t_{1}-t_{2}\right)}\right\}+\frac{D}{\alpha+c} \\
& \sin c e \frac{\partial C_{s h o}}{\partial t_{1}}=0, \frac{\partial O C}{\partial t_{1}}=0
\end{aligned}
$$$$
X=C+c_{p}(S+R)+C_{h o l}+C_{s h o}+D C+O C
$$$$
\frac{\partial X}{\partial t_{2}}=c_{p}\left(\frac{\partial s}{\partial t_{2}}+\frac{\partial R}{\partial t_{2}}\right)+\frac{\partial C_{h o l}}{\partial t_{2}}+\frac{\partial C_{s h o}}{\partial t_{2}}+\frac{\partial D C}{\partial t_{2}}+\frac{\partial O C}{\partial t_{2}}
$$$$
\frac{\partial T c}{\partial t_{2}}=\frac{1}{T}\left[c_{p}\left(\frac{\partial s}{\partial t_{2}}+\frac{\partial R}{\partial t_{2}}\right)+\frac{\partial C_{h o l}}{\partial t_{2}}+\frac{\partial C_{s h o}}{\partial t_{2}}+\frac{\partial D C}{\partial t_{2}}+\frac{\partial O C}{\partial t_{2}}\right]
$$$$
\text { Now, } \frac{\partial T c}{\partial t_{2}}=0
$$$$
\frac{1}{T}\left[c_{p}\left(\frac{\partial s}{\partial t_{2}}+\frac{\partial R}{\partial t_{2}}\right)+\frac{\partial C_{h o l}}{\partial t_{2}}+\frac{\partial C_{s h o}}{\partial t_{2}}+\frac{\partial D C}{\partial t_{2}}+\frac{\partial O C}{\partial t_{2}}\right]=0
$$$$
\Rightarrow \frac{1}{T}\left[c_{p}\left\{D e^{(\alpha+c)\left(t_{2}-t_{1}\right)}+\frac{D(\alpha+c)}{\beta+c}\left\{e^{(\beta+c)\left(t_{d}-t_{2}\right)}-1\right\} e^{(\alpha+c)\left(t_{2}-t_{1}\right)}-D e^{(\beta+c)\left(t_{d}-t_{2}\right)} e^{(\alpha+c)\left(t_{2}-t_{1}\right)}\right\}\right.
$$$$
+c_{h}\left[\begin{array}{l}
\left\{D e^{(\alpha+c)\left(t_{2}-t_{1}\right)}+\frac{D(\alpha+c)}{\beta+c}\left\{e^{(\beta+c)\left(t_{d}-t_{2}\right)}-1\right\} e^{(\alpha+c)\left(t_{2}-t_{1}\right)}-D e^{(\beta+c)\left(t_{d}-t_{2}\right)} e^{(\alpha+c)\left(t_{2}-t_{1}\right)}\right\}\left\{\frac{1}{\alpha+c}-\frac{e^{(\alpha+c)\left(t_{1}-t_{2}\right)}}{\alpha+c}\right\} \\
+\left\{S-W+\frac{D}{\alpha+c}\right\} e^{(\alpha+c)\left(t_{1}-t_{2}\right)}-\frac{D}{\alpha+c}+\frac{D}{\beta+c}\left\{1-e^{(\beta+c)\left(t_{d}-t_{2}\right)}\right\}
\end{array}\right]
$$$$
+c_{d} \alpha\left\{D e^{(\alpha+c)\left(t_{2}-t_{1}\right)}+\frac{D(\alpha+c)}{\beta+c}\left\{e^{(\beta+c)\left(t_{d}-t_{2}\right)}-1\right\} e^{(\alpha+c)\left(t_{2}-t_{1}\right)}-D e^{(\beta+c)\left(t_{d}-t_{2}\right)} e^{(\alpha+c)\left(t_{2}-t_{1}\right)}\right\}\left\{\frac{1}{\alpha+c}-\frac{e^{(\alpha+c)\left(t_{1}-t_{2}\right)}}{\alpha+c}\right\}+
$$$$
\left[\left\{S-W+\frac{D}{\alpha+c}\right\} e^{(\alpha+c)\left(t_{1}-t_{2}\right)}-\frac{D}{\alpha+c}\right]+c_{d} \beta\left[\frac{D}{\beta+c}\left\{1-e^{(\beta+c)\left(t_{d}-t_{2}\right)}\right\}\right]=0
$$

, sin $c e \frac{\partial R}{\partial t_{2}}=0$ and $\frac{\partial C_{\text {sho }}}{\partial t_{2}}=0$ and $\frac{\partial O C}{\partial t_{2}}=0$ 


$$
\begin{aligned}
& X=C+c_{p}(S+R)+C_{h o l}+C_{s h o}+D C+O C \\
& \frac{\partial X}{\partial t_{d}}=c_{p}\left(\frac{\partial s}{\partial t_{d}}+\frac{\partial R}{\partial t_{d}}\right)+\frac{\partial C_{h o l}}{\partial t_{d}}+\frac{\partial C_{s h o}}{\partial t_{d}}+\frac{\partial D C}{\partial t_{d}}+\frac{\partial O C}{\partial t_{d}} \\
& \frac{\partial T c}{\partial t_{d}}=\frac{1}{T}\left[c_{p}\left(\frac{\partial s}{\partial t_{d}}+\frac{\partial R}{\partial t_{d}}\right)+\frac{\partial C_{h o l}}{\partial t_{d}}+\frac{\partial C_{s h o}}{\partial t_{d}}+\frac{\partial D C}{\partial t_{d}}+\frac{\partial O C}{\partial t_{d}}\right] \\
& \text { Now, } \frac{\partial T c}{\partial t_{d}}=0 \\
& \frac{1}{T}\left[c_{p}\left(\frac{\partial s}{\partial t_{d}}+\frac{\partial R}{\partial t_{d}}\right)+\frac{\partial C_{h o l}}{\partial t_{d}}+\frac{\partial C_{s h o}}{\partial t_{d}}+\frac{\partial D C}{\partial t_{d}}+\frac{\partial O C}{\partial t_{d}}\right]=0 \\
& \Rightarrow \frac{1}{T}\left[c_{p}\left\{D e^{(\beta+c)\left(t_{d}-t_{2}\right)} e^{(\alpha+c)\left(t_{2}-t_{1}\right)}-\delta D\right\}+c_{h}\left[\frac{D}{\beta+c}\left\{e^{(\beta+c)\left(t_{d}-t_{2}\right)}-1\right\}\right]-c_{b} \delta D\left(T-t_{d}\right)+\right. \\
& c_{d} \alpha\left[\left\{D e^{(\beta+c)\left(t_{d}-t_{2}\right)} e^{(\alpha+c)\left(t_{2}-t_{1}\right)}\right\}\left\{\frac{1}{\alpha+c}-\frac{e^{(\alpha+c)\left(t_{1}-t_{2}\right)}}{\alpha+c}\right\}\right]-c_{d} \beta\left[\frac{D}{\beta+c}\left\{1-e^{(\beta+c)\left(t_{d}-t_{2}\right)}\right\}\right]-c_{l}(1-\delta) D=0 \\
& X=C+c_{p}(S+R)+C_{h o l}+C_{\text {sho }}+D C+O C \\
& \frac{\partial X}{\partial T}=c_{p}\left(\frac{\partial s}{\partial T}+\frac{\partial R}{\partial T}\right)+\frac{\partial C_{h o l}}{\partial T}+\frac{\partial C_{s h o}}{\partial T}+\frac{\partial D C}{\partial T}+\frac{\partial O C}{\partial T} \\
& \frac{\partial T c}{\partial T}=\frac{1}{T}\left[c_{p}\left(\frac{\partial s}{\partial T}+\frac{\partial R}{\partial T}\right)+\frac{\partial C_{h o l}}{\partial T}+\frac{\partial C_{s h o}}{\partial T}+\frac{\partial D C}{\partial T}+\frac{\partial O C}{\partial T}\right]-\left(1 / T^{2}\right) X \\
& \text { Now, } \frac{\partial T c}{\partial T}=0 \\
& \frac{1}{T}\left[c_{p}\left(\frac{\partial s}{\partial T}+\frac{\partial R}{\partial T}\right)+\frac{\partial C_{h o l}}{\partial T}+\frac{\partial C_{s h o}}{\partial T}+\frac{\partial D C}{\partial T}+\frac{\partial O C}{\partial T}\right]-\frac{1}{T^{2}}\left[C+c_{p}(S+R)+C_{h o l}+C_{s h o}+D C+O C\right]=0 \\
& \Rightarrow \frac{1}{T}\left[c_{p} \delta D+c_{b} \delta D\left(T-t_{d}\right)+c_{l}(1-\delta) D\right]-\frac{1}{T^{2}}\left[C+c_{p}(S+R)+C_{h o l}+C_{s h o}+D C+O C\right]=0
\end{aligned}
$$

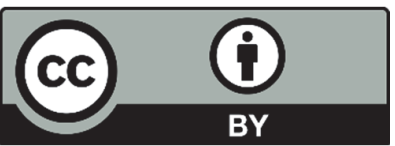

(C) 2018 by the authors; licensee Growing Science, Canada. This is an open access article distributed under the terms and conditions of the Creative Commons Attribution (CC-BY) license (http://creativecommons.org/licenses/by/4.0/). 